\title{
O Efeito Framing na Tomada de Decisão Contábil: Perspectiva dos Profissionais de Contabilidade dos Estados do Rio Grande do Norte e Pará ${ }^{1}$
}

\section{The Framing Effect Decision Making in Accounting: Perspective of Professional Accounting in the states of Rio Grande do Norte and Pará}

\author{
Joana Darc Medeiros Martins \\ Mestre em Ciências Contábeis. Professora do Departamento de Ciências Contábeis - UFRN \\ Endereço: CCSA - Departamento de Ciências Contábeis. Av. Senador Salgado Filho, 3000, Campus \\ Universitário, Lagoa Nova. CEP: 59.072-970 - Natal - RN, Brasil, e-mail: joanadarc@ufrnet.br \\ Daniele da Rocha Carvalho \\ Mestre em Ciências Contábeis. Professora do Departamento de Ciências Contábeis - UFRN \\ Endereço: CCSA - Departamento de Ciências Contábeis. Av. Senador Salgado Filho, 3000, Campus \\ Universitário, Lagoa Nova. CEP: 59.072-970 - Natal - RN, e-mail: danielerocha@ufrnet.br
}

\section{Ticiane Lima dos Santos}

Mestre em Administração. Professora de graduação e pós-graduação, consultora de empresa e de IES. Universidade Federal Rural da Amazônia, Diretoria.

Endereço: Travessa Primeira de Queluz, São Brás, CEP:66.090-520, Belém, PA - Brasil, Telefone: (91) 88286102 e-mail: $\underline{\text { ticianesantos@yahoo.com.br }}$

\section{José Dionísio Gomes da Silva}

Professor Associado da UFRN e do Programa Multiinstitucional e Inter-regional de Pós-Graduação em Ciências Contábeis UnB/UFRN/UFPB.

Endereço: Universidade Federal do Rio Grande do Norte. Departamento de Ciências Contábeis, Av. Senador Salgado Filho, S/N, Campus Universitário, Lagoa Nova, Natal - RN -Brasil, CEP 59076-000, e-mail: dionisio@ufrnet.br, fone: (84) 3207-6602.

\section{RESUMO}

O estudo tem como objetivo analisar o impacto da racionalidade limitada em um ambiente de decisão com base em informações contábeis na perspectiva de profissionais de contabilidade. Para isso, aplicou-se um questionário validado do efeito Framing de escolha sobre o risco com 172 profissionais da contabilidade nas cidades de Natal/RN e Belém/PA. Quanto à metodologia foi descritiva e quantitativa com aplicação de testes, utilizando a replicação de um estudo realizado com estudantes por Dantas e Macedo (2012). Os resultados apresentados evidenciam que os profissionais, quando expostos a situações negativas são propensos ao risco e, quando expostos a situações positivas, possuem aversão à perda. A teoria dos prospectos é identificada quando o respondente associa a alternativa A da primeira decisão com a D da segunda decisão. Na pesquisa apenas 30,81\% realizaram esta associação, e em outra parte, sendo o maior percentual, $37,79 \%$, verificou-se a utilização de viés heurístico no que tange à autoconfiança excessiva. Este ponto diferencia-se da pesquisa com estudantes, pois a maior concentração (41\%) se deu com ênfase na

\footnotetext{
${ }^{1}$ Artigo recebido em 01.07.2013. Revisado pelos pares em 31.07.2013. Ajustado e Aceito para publicação em 11.09.2013. Recomendado para publicação por José Ribamar Marques de Carvalho (Editor Científico). Publicado em 15.09.2013. Organização responsável UACC/CCJS/UFCG.
} 
teoria dos prospectos, utilizando-se da abordagem com viés do enquadramento dos resultados, Nas questões que verificam o efeito da pseudocerteza, observou-se que 17,44\% dos profissionais de contabilidade foram influenciados por uma manipulação da certeza. Entretanto, na pesquisa realizada com estudantes, essa influencia foi de $40 \%$; assim, pode-se inferir que os profissionais são menos influenciados pela manipulação da certeza. Pode-se observar no teste qui-quadrado de Pearson (Teste $\chi^{2}$ ), que não houve diferença no padrão de resposta entre Natal/RN e Belém/PA.

Palavras Chaves: Efeito Framing. Teoria do prospecto. Profissionais de Contabilidade.

\section{ABSTRACT}

The study aims to analyze the impact of bounded rationality in a decision environment based on accounting information from the perspective of accounting professionals. For this, we applied a validated questionnaire Framing effect of choice on the risk with 172 accounting professionals in the cities of Natal / RN and Belém / PA. Regarding the methodology was descriptive and quantitative application to test, using a replication of a study conducted with students by Dantas and Macedo (2012). The study results indicate that professionals when exposed to negative situations are prone to risk and, when exposed to positive situations, have loss aversion. The theory of the prospectus is identified when the respondent associates alternative $A$ of the first decision with the $D$ in the second decision. Only $30.81 \%$ in the survey conducted this association, and elsewhere, being the highest, $37.79 \%$, there was the use of heuristic bias regarding the overconfidence. This point differs from research with students as the highest concentration (41\%) occurred with an emphasis on the theory of prospectuses, using the approach biased the results framework, issues In looking at the effect of pseudo sure, there that $17.44 \%$ of accounting professionals were influenced by a manipulation of certainty. However, the survey of students, this influence was $40 \%$, so it can be inferred that professionals are less influenced by the manipulation of certainty. It can be observed in the chi-square test, there was no difference in the response pattern between Natal / RN and Belém / PA.

Key Words: Framing Effect. Prospect theory. Professional Accounting.

\section{INTRODUÇÃO}

As transformações do mundo globalizado ocorreram no âmbito legal, fiscal, econômico e patrimonial. E a contabilidade faz parte dessa mudança à medida que os demonstrativos financeiros são alterados para uma convergência de padrão internacional implicando em informações mais transparentes para a tomada de decisão. Para Marion (2009), a ênfase que deverá ser atribuída aos demonstrativos é a de interpretar, entender, analisar os relatórios contábeis, para tirar conclusões úteis para assessorar as tomadas de decisão.

O destaque desta alteração em relação ao estudo do efeito Framing está no inciso IV Registro pelo valor original que está subdividida em: a) custo corrente; b) valor realizável; c) valor presente; d) valor justo e e) atualização monetária. Assim, a tendência da contabilidade está relacionada com a substância e realidade econômica (essência) e não apenas a sua forma legal (forma). Incluindo assim o juízo do valor do profissional contábil para produzir informações com mais qualidade e utilidade para tomada de decisão.

Para Daft (1999) existem condições que afetam a tomada de decisão organizacional, por isso o individuo deverá analisar a possibilidade de fracasso 
entre o grau baixo e alto considerando as variáveis de certeza, risco, incerteza e ambuiguidade.

Para Langaray e Beuren (2001) constantemente as pessoas enfrentam situações que exigem respostas que utilizam os diversos meios: natureza impulsiva, juízo de valor, previsibilidade e racionalidade para a resolução do problema.

Assim a teoria do prospecto investiga o julgamento para a tomada de decisão aplicando princípios psicológicos (KAHNEMAN; TVERSKY, 1979). Considerando que o individuo demonstra racionalidade limitada no efeito das preferências na tomada de decisão, torna-se imprescindível o conhecimento dos aspectos psicológicos ou cognitivos que o limitam (PINTO; MACEDO; ALVES 2012).

Para Santos (2010), o desenvolvimento psicológico tem interferência do social para o individual. Desta forma, a estrutura cognitiva do individuo exerce influência para a tomada de decisão. Para Vygotsky (1987), o ambiente social está diretamente relacionado com o desenvolvimento cognitivo do individuo, desta forma se o individuo mudar de local, cultura e ambiente o desenvolvimento também mudará. Sendo assim a decisão poderá ser influenciada pelo desenvolvimento psicológico do individuo.

Segundo Dantas e Macedo (2012) tomar decisão é uma atividade complexa e está sob a concepção do individuo racional, o que Simon (1955) define como principio da racionalidade limitada. Para Dantas e Macedo (2012), o efeito framing é um dos fenômenos que mais conflitam com o paradigma do homem racional.

Segundo Levin, Gaeth e Schreiber (2002) há três tipos de efeito framing: o de Atributo que se refere ao sucesso ou insucesso; o de Objetivo que se refere à mensagem persuasiva e o efeito de Framing de escolha sob o risco que ocorre quando o problema está sendo apresentado positivamente ou negativamente. $\mathrm{E}$ este estudo restringe-se ao efeito Framing de escolha sob risco no cenário de decisão contábil-financeiro.

Considerando esses aspectos fica definido a seguinte situação-problema: Qual o impacto da racionalidade limitada em um ambiente de decisão com base em informações contábeis na perspectiva de profissionais de contabilidade?

No intuito de responder a problemática o estudo objetiva analisar o impacto da racionalidade limitada em um ambiente de decisão com base em informações contábeis na perspectiva de profissionais de contabilidade, baseado na teoria dos Prospectos de Kahneman e Tversky (1979) e a racionalizada limitada de Simon (1995).

Além desta introdução o artigo apresenta o referencial teórico, os procedimentos metodológicos, resultados, considerações finais e as referências. 


\section{REFERENCIAL TEÓRICO}

\subsection{Teorias tradicionais e modernas de finanças}

Todo o estudo das finanças em nível mundial está fundamentado em dois conceitos principais: risco e retorno. A premissa básica é que os investidores são afetos ao retorno, mas não aos riscos, o que leva à conclusão que as pessoas somente investem em ativos mais arriscados se esperarem obter um maior retorno nesse investimento.

$O$ retorno de um investimento, de maneira geral, pode ser expresso em unidades monetárias, como sendo a diferença entre o total recebido pelo investimento e a quantia investida (BRIGHAM; EHRHARDT, 2006). Porém, conforme afirma Iudícibus (2009, p. 105), “Expressar a rentabilidade em termos absolutos [unidades monetárias] tem uma utilidade informativa bastante reduzida". Essa utilidade reduzida está relacionada a dois problemas apontados por Brigham e Ehrhardt (2006, p. 203):

\footnotetext{
“(1) Para fazer um julgamento correto a respeito do retorno, você precisa conhecer a escala (tamanho) do investimento; um retorno de \$ 100 em um investimento de $\$ 100$ é muito bom (assumindo que o investimento seja mantido por 1 ano), mas um retorno de $\$ 100 \mathrm{em}$ um investimento de $\$ 10.000$ seria bastante baixo; (2) você também precisa conhecer o tempo oportuno de ocorrência desse retorno: um retorno de \$ 100 sobre um investimento de \$ 100 é um retorno muito bom caso ele ocorra após 1 ano, mas o mesmo retorno nessa moeda após 20 anos não seria muito bom".
}

Dessa forma, a solução é expressar os resultados dos investimentos sob a forma de taxas de retorno ou retornos percentuais expressos em bases temporais (mensal, semestral, anual, etc.). O conceito de retorno, conforme afirmam Brigham e Ehrhardt (2006, p. 202), "oferece aos investidores uma forma conveniente de expressar o desempenho financeiro de um investimento".

Porém, o retorno de um investimento está sujeito à incerteza financeira de se concretizar. Essa incerteza financeira é denominada "risco" (CHANCELLOR, 2001). O risco de um ativo pode ser analisado de duas formas: isoladamente ou em uma carteira de ativos.

Para medir o risco isolado de um ativo, utiliza-se uma medida de concentração da distribuição de probabilidade, que é o desvio padrão. Quanto menor o desvio padrão, mais estreita é a distribuição de probabilidade, o que significa um menor risco (BRIGHAM; EHRHARDT, 2006).

Por sua vez, quando se pretende medir o risco de uma carteira de ativos, o retorno esperado sobre essa carteira é a média ponderada dos retornos 
esperados sobre cada um dos ativos que compõem essa carteira. Vale salientar, porém, que o risco da carteira não é a média ponderada dos desvios padrão dos ativos individuais; o risco da carteira, ou seja, seu desvio padrão é menor que a média ponderada dos riscos isolados dos ativos. Conforme afirmam Brigham e Ehrhardt (2006, p. 215), "é teoricamente possível combinar ações que são bastante arriscadas individualmente se medidas por seus desvios padrão e formar uma carteira completamente livre de risco".

\subsection{Finanças comportamentais - Teoria dos prospectos}

Shefrin (2002) define finanças comportamentais como a aplicação da psicologia do comportamento ao comportamento dos participantes do mercado financeiro enquanto tomadores de decisão.

Segundo Ariely (2008, p. 196) "nos pressupostos da economia tradicional, todas as decisões humanas são racionais e instruídas, motivadas por um conceito preciso do valor de todos os bens e serviços e da quantidade de felicidade (utilidade) que todas as decisões têm a probabilidade de produzir". Corroborando, Mosca (2009, p. 4) afirma que "A premissa ou hipótese básica que dá sustentação à maior parte da teoria econômica e financeira moderna está calcada na racionalidade dos agentes econômicos, sejam eles indivíduos ou empresas". Nessa mesma linha, Dantas e Macedo (2012) defendem que nas teorias tradicionais e modernas de finanças, a concepção de "indivíduo racional" é amplamente aceita como modelo normativo do comportamento econômico.

Porém, surgido da combinação da psicologia com as finanças, o campo das finanças comportamentais se fundamenta em um grande número de evidências no campo da psicologia que indicam que as pessoas não têm um comportamento racional quando o assunto é relacionado aos seus investimentos (BRIGHAM; EHRHARDT, 2006).

Esse é o entendimento de Ariely (2008, p. 196) quando acrescenta que "os economistas comportamentais, por outro lado, acreditam que somos suscetíveis a influências do ambiente imediato (o que chamamos de efeito do contexto), a emoções irrelevantes, à imprevidência e outras formas de irracionalidade".

Conforme afirmam Yoshinaga et al. (2004), quase todas as teorias tradicionais de Finanças foram construídas a partir de uma abordagem microeconômica neoclássica, cujo paradigma central é a racionalidade dos agentes econômicos. O paradigma tradicional possui a vantagem da simplicidade e facilidade de modelagem do ponto de vista do pesquisador. Mesmo assim, a validade deste arcabouço para descrever o comportamento dos mercados é uma questão de natureza empírica. Se as teorias baseadas no agente 
racional fossem capazes de explicar satisfatoriamente todos ou os mais importantes fenômenos investigados pela literatura de finanças, não haveria razão para se questionar seus fundamentos e propor abordagens alternativas.

Porém, um significativo conjunto de evidências empíricas produzidas em estudos desenvolvidos nas últimas décadas, revela que as teorias baseadas na racionalidade dos indivíduos não são capazes de explicar a contento diversos fenômenos regularmente observados nos mercados financeiros (YOSHINAGA et al, 2004).

Foi nesse contexto que, no final da década de 1970, surge as finanças comportamentais, com a publicação dos trabalhos de Kahneman e Tverski sobre o comportamento e o processo de tomada de decisão de uma pessoa em condições de risco. Nesses trabalhos, os autores apresentavam problemas a diferentes grupos de pessoas, que eram levados a tomar decisões baseadas no benefício (ganho ou perda) e no risco envolvidos nessas decisões. Desses estudos surgiu o conceito de aversão à perda, que é um dos mais importantes conceitos das finanças comportamentais. Segundo esse conceito, as pessoas sentem mais a dor da perda que o prazer obtido com um ganho equivalente (HALFELD; TORRES, 2001).

Após mais de uma década sendo suplantado pelos modelos tradicionais de finanças na explicação do comportamento do mercado, o estudo das finanças comportamentais se fortaleceu a partir da constatação de anomalias do mercado financeiro não possíveis de ser explicadas pelos modelos tradicionais.

\subsubsection{Aversão à perda}

O principal conceito originado pelo estudo das finanças comportamentais, foi proposto originalmente por Kahneman e Tverski no final da década de 1970 (HALFELD; TORRES, 2001). Kahneman e Tverski contrariam a Teoria da Utilidade Esperada, segundo a qual o investidor avalia o risco de um investimento de acordo com a mudança que ele pode provocar em sua riqueza, e passam a sugerir uma nova curva de risco-utilidade que, segundo a Teoria da Unidade Esperada seria uma reta passando pela origem no plano cartesiano valor-ganho/perda, conforme demonstrado na Figura 2 (ROGERS et al., 2007). 
Figura 2 - Curvas de risco-utilidade

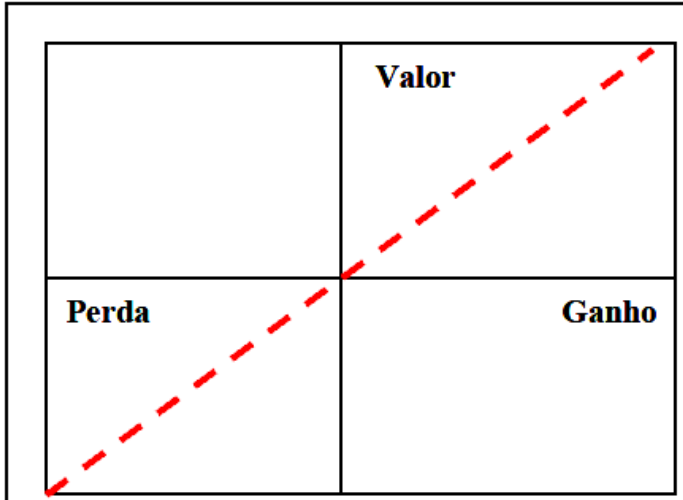

Teoria da Utilidade

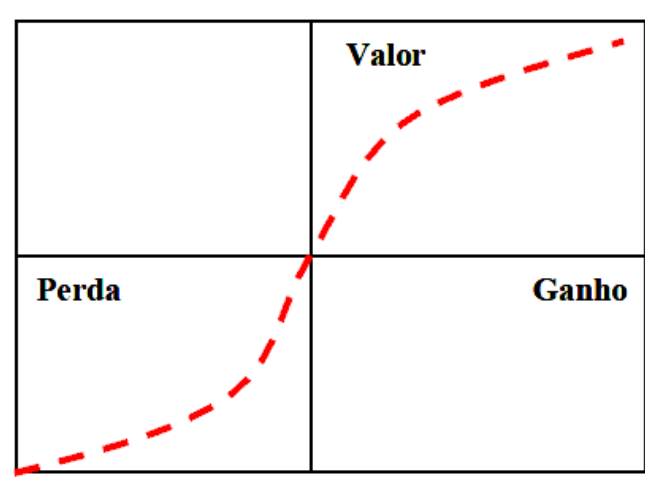

Teoria do Prospecto

Fonte: Rogers et al. (2007, p. 5)

Lima (2003, p. 11) expõe que "o investidor, segundo as Finanças Comportamentais, avalia o risco de um investimento com base em um ponto de referência a partir do qual, mede ganhos e perdas". Lima (2003) ainda acrescenta que existem pessoas que tem aversão à perda e que isto não significa a mesma coisa de aversão ao risco. "Frente a uma perda, frequentemente as pessoas topam o risco de perder ainda mais somente pela chance de não 'realizar' a perda". (LIMA, 2003, p. 12)

Segundo Kahneman e Tversky (1979 apud Lima 2003, p. 12) “a perda representa 2,5 vezes mais impacto que um ganho no mesmo valor". Complementando esse entendimento, Mosca (2009) atenta para o fato que, no que diz respeito à sensibilidade que as pessoas têm a perdas e ganhos, quanto mais um indivíduo ganha, menor é o acréscimo de satisfação ou prazer que sente.

\subsubsection{Autoconfiança excessiva}

O otimismo exagerado ou a autoconfiança excessiva, é definido por Mosca (2009, p. 58) como sendo o chamado viés de auto-atribuição que

\footnotetext{
"faz com que atribuamos a nós mesmos o crédito por eventos passados cujos resultados foram favoráveis, mas sobre os quais tivemos pouca ou nenhuma influência. Mais precisamente, o indivíduo passa a se gabar de decisões passadas que resultaram em sucesso, ao passo que os fracassos são atribuídos a fatores externos e fora de seu controle. É o que Langer e Roth ${ }^{2}$ (1975) resumem por: 'Cara eu ganho, coroa é falta de sorte'. A implicação de tal tendência
}

\footnotetext{
${ }^{2}$ LANGER, E.; ROTH, J. Heads I win, tails it's chance: the illusion f control as a function of the sequence of outcomes in a purely chancetask. Journal of Personality and Social Psychology, 1975.
} 
comportamental para o universo dos investimentos é que ganhos passam a ser assimilados pelo aplicador como prova de conhecimento e competência, ao passo que perdas são atribuídas a fatores aleatórios relacionados à macroeconomia e aos movimentos erráticos dos mercados."

Mosca (2009, p. 59) chama a atenção para o fato que "O excesso de confiança e o viés da auto-atribuição levam o investidor a acreditar ser capaz de prever os movimentos do mercado, inclusive no curto prazo e mesmo durante momentos de volatilidade".

Milanez (2003) ressalta que se os agentes aprendessem com os próprios erros, esses erros poderiam ser eliminados do processo de tomada de decisão em condições de risco. Isso não acontece, conforme estudos psicológicos e econômicos apontam, porque existem limitadores do processo de aprendizado, sendo um dos principais o excesso de otimismo/confiança das pessoas quando estas fazem julgamentos sobre eventos e sobre si mesmas.

\section{PROCEDIMENTOS METODOLÓGICOS}

Para definir o critério de classificação adotado nesta pesquisa, utilizou-se como referencial o conceito de Vergara (2004, p.46), que diz "a pesquisa pode ser classificada quanto aos fins e quanto aos meios".

Quanto aos fins trata-se de uma pesquisa descritiva que tem por finalidade observar, registrar e analisar os fenômenos, descrevendo suas características. Segundo Vergara (2004, p.47), “a pesquisa descritiva expõe características de determinada população ou de determinado fenômeno".

Quanto aos meios de investigação, o estudo classifica-se como pesquisa bibliográfica e de campo. A pesquisa bibliografia foi realizada mediante revisão da literatura, com o intuito de coletar informações e conhecimentos para atingir os objetivos do trabalho e propiciar um melhor entendimento sobre o tema abordado.

Segundo Vergara (2004, p.48): “pesquisa bibliográfica é o estudo sistemático desenvolvido com base em material publicado em livros, revistas, jornais, redes eletrônicas, isto é, material acessível ao público em geral".

No entendimento de Vergara (2004, p.47), "pesquisa de campo é investigação empírica realizada no local onde ocorre ou ocorreu um fenômeno ou que dispõe de elementos para explicá-lo". Dessa forma, a observação dos fatos, foi realizada em Natal/RN e Belém/PA. A escolha dessas cidades foi por conveniência e acessibilidade dos autores.

A amostragem utilizada no estudo foi do tipo não probabilístico, uma vez que obtida por meios que não envolvem o acaso. Assim, em Belém/PA os 
questionários foram aplicados em um evento do Conselho Regional de Contabilidade no mês de maio de 2012 e em Natal/RN foram aplicados em turmas de pós-graduação durante os meses de maio e junho de 2012. A seleção dessas cidades foi realizada por conveniência. Trata-se de uma técnica de amostragem onde o investigador seleciona os casos que estão mais disponíveis (GONZÁLEZ RIOS, 1997).

Os respondentes foram selecionados pela estreita relação desses profissionais com as informações contábeis. Isto é, se os profissionais contábeis são afetados pelo efeito formulação em situações envolvendo informações gerenciais em redução de custos, provavelmente os demais estudantes também o serão.

Os questionários foram baseados no estudo de Dantas e Macedo, 2012, que por sua vez se baseou na estratégia utilizada por Kahneman e Tversky (1979) no estudo sobre o processo decisório humano em condições de risco. Duas versões para a mesma situação foram utilizadas, possibilitando a formulação de dois questionários (1 e 2). Contudo, diferentemente do trabalho de Kahneman e Tversky (1979), os sujeitos da pesquisa não responderam aos dois questionários. $\mathrm{O}$ objetivo aqui foi impossibilitar qualquer viés nas respostas, tendo em vista que a única diferença entre a questão é a forma de apresentação ou contextualização das situações.

O questionário continha uma questão apresentada de forma diferente para questionário 1 e 2, tendo o objetivo de verificar se a maneira como as informações contábeis são escritas pode influenciar a tomada de decisão. Para o questionário 1 a questão trata do campo das perdas e o 2 para o campo dos ganhos.

Trata-se da mesma situação estruturada ou apresentada de duas maneiras distintas. Aos respondentes foi pedido para avaliar a decisão em função da situação econômica em que vivencia a empresa. De posse de tais situações foi definida a seguinte hipótese de pesquisa:

$\mathrm{H}_{1}$ : No questionário 2, as questões foram influenciadas pelo ganho, a maioria dos respondentes consideraria como sendo a melhor decisão; enquanto que no questionário 1 , onde as questões foram influenciadas pela perda, a maioria dos respondentes avaliaria a decisão como ruim.

Caso $\mathrm{H}_{1}$ seja verdadeira, poder-se-á concluir que a forma de apresentação da situação exerceu influência significativa na decisão dos profissionais, haja vista ser essa a única diferença dessa questão nos dois questionários.

No total, foram enviados 300 e-mails e 84 foram aplicados pessoalmente, sendo que o total de respondentes corresponde a 172. Para a análise dos dados recorreu-se a estatística descritiva. Também procurou verificar se outras variáveis - cidade, titulação (proxy para conhecimento), idade (proxy para 
experiência e conhecimento), gênero (masculino ou feminino) - na tentativa de identificar a influência nos padrões de respostas observados.

Para verificar se existem diferenças significativas na percepção dos profissionais, utilizou-se da estatística qui-quadrado de Pearson (Teste $\chi^{2}$ ), apenas na questão 1, por se apresentar de formas diferentes, ou seja, um questionário relacionava a ganhos e o outro questionário relacionava a perdas (efeito formulação).

Para as demais questões, foi verificado as diferenças significativas entre os respondentes de Natal/RN e Belém/PA.

Esse teste foi utilizado no intuito de testar se duas variáveis são independentes. Caso o valor de significância seja pequeno o suficiente (convencionalmente Sig. deve ser menor que 0.05) então a hipótese de que as variáveis são independentes é rejeitada e a hipótese de que elas são, de alguma maneira, relacionadas, é aceita (FIELD, 2000, p. 65).

Esse teste permite inferir se o padrão de respostas (a proporção de indivíduos que responderam uma alternativa e a proporção dos sujeitos que responderam a outra opção) nos grupos analisados é significativamente diferente (se existir associação) ou não (se não for encontrada associação estatística).

Para o teste ser significativo é imperativa a observância dos seguintes pressupostos: cada pessoa deve ser computada uma única vez e as frequências esperadas devem ser maiores que 5. Trata-se da frequência que se espera que aconteça em cada categoria para que a hipótese nula de que não existe diferença entre os grupos ocorra. O teste $\chi^{2}$ verifica se a diferença entre os casos observados e os esperados (calculados com base no número de observações) é grande o suficiente para ser considerada significativa (SIEGEL; CASTELLAN JR., 2006).

A análise dos dados observou essas exigências. A tabulação e análise dos dados, bem como os testes estatísticos foram realizados através do software estatístico SPSS 13.0 - Statistical Package for the Social Sciences. A seguir são apresentados e discutidos os resultados do estudo.

\section{APRESENTAÇÃO E DISCUSSÃO DOS RESULTADOS}

\subsection{Perfil dos Respondentes}

No intuito de estabelecer o perfil do profissional respondente, se fez questionamentos básicos, sobre o gênero, idade, titulação e cidade. 
Tabela 1 - Gênero

\begin{tabular}{c|c|c}
\hline & Frequência & Percentual \\
\hline Masculino & 93 & 65,0 \\
\hline Feminino & 79 & 55,0 \\
\hline Total & 172 & 100,0 \\
\hline
\end{tabular}

Fonte: Dados da pesquisa, 2012

Em relação ao gênero os profissionais da contabilidade pesquisados concentraram em $65 \%$ no sexo masculino.

Tabela 2 - Idade

\begin{tabular}{c|c|c}
\hline & Frequência & Percentual \\
\hline 19 a 24 anos & 30 & 17,0 \\
\hline 25 a 29 anos & 33 & 19,0 \\
\hline 30 a 34 anos & 29 & 17,0 \\
\hline 35 a 39 anos & 20 & 12,0 \\
\hline Mais de 40 anos & 60 & 35,0 \\
\hline Total & 172 & 100,0 \\
\hline
\end{tabular}

Fonte: Dados da pesquisa, 2012

Quanto à caracterização da idade verificou-se que o publico pesquisado concentra-se na faixa etária de mais de 40 anos, com $35 \%$ e se for analisado a partir dos 30 anos, encontra-se $64 \%$ dos profissionais da contabilidade.

\begin{tabular}{c|c|c}
\multicolumn{3}{c}{ Tabela 3 - Titulação } \\
\hline & Frequência & Percentual \\
\hline Graduação & 109 & 63,0 \\
\hline Pós Graduação & 63 & 37,0 \\
\hline Total & 172 & 100,0 \\
\hline
\end{tabular}

Fonte: Dados da pesquisa, 2012

Quanto à formação a maior concentração é na graduação com 63\% dos entrevistados e 37\% na pós-graduação.

Tabela 4 - Cidade

\begin{tabular}{c|c|c}
\hline & Frequência & Percentual \\
\hline Natal & 54 & 31,0 \\
\hline Belém & 112 & 65,0 \\
\hline Outras & 6 & 4,0 \\
\hline Total & 172 & 100,0 \\
\hline \multicolumn{2}{r}{} \\
\end{tabular}

Fonte: Dados da pesquisa, 2012 
Em relação às cidades escolhidas por conveniência forma Belém e Natal e verifica-se $65 \%$ em Belém.

\subsection{Análise Geral}

Este artigo originou-se da escolha de uma metodologia de replicação de um questionário validado anteriormente por Dantas e Macedo (2012). Este questionário possui quatro questões relativas ao processo decisório, que são analisadas individualmente, e duas delas, a 2 e a 4 , analisadas de forma conjunta. Os vieses de decisão analisados na pesquisa estão apresentados no Quadro 1.

Quadro 1 - Vieses de decisão analisados

\begin{tabular}{|c|lr|l|}
\hline Questão & \multicolumn{1}{|c|}{ Viés de decisão } & \multicolumn{1}{c|}{ Descrição } \\
\hline 1 & $\begin{array}{l}\text { Decisões afetadas pelo } \\
\text { enquadramento da escolhas }\end{array}$ & $\begin{array}{l}\text { Reflete, com maior incidência, sobre a soma dos } \\
\text { resultados de todas as escolhas indesejáveis } \\
\text { predominando sobre a soma das escolhas } \\
\text { desejáveis, isto é, o enquadramento do problema } \\
\text { é combinado em duas partes, tendo como } \\
\text { resultado uma reversão de preferências. Na } \\
\text { realidade, essa inconsistência viola os requisitos } \\
\text { fundamentais da tomada de decisão racional, } \\
\text { consistente e coerente. }\end{array}$ \\
\hline 2 e 4 & $\begin{array}{l}\text { Decisões afetadas pelos } \\
\text { efeitos } \\
\text { pseudocerteza enquadrado } \\
\text { nas escolhas }\end{array}$ & $\begin{array}{l}\text { Relacionado ao fato dos indivíduos darem um } \\
\text { peso menor a eventos de alta probabilidade, mas } \\
\text { ponderarem adequadamente eventos que são } \\
\text { certos. Aqui a inconsistência de julgamento é } \\
\text { observada, pela facilidade de manipulação da } \\
\text { percepção de certeza, originando o efeito certeza } \\
\text { e o efeito pseudocerteza. }\end{array}$ \\
\hline 3 & $\begin{array}{l}\text { Decisões afetadas pelo } \\
\text { enquadramento } \\
\text { resultados }\end{array}$ & $\begin{array}{l}\text { Aqui a localização do referencial é construída } \\
\text { para se determinar se uma decisão está } \\
\text { enquadrada positiva ou negativamente, afetando } \\
\text { assim a preferência do tomador de decisão. }\end{array}$ \\
\hline
\end{tabular}

Fonte: Adaptado de Andrade, Alyrio e Amcedo (2007)

O objetivo de análise da questão 1 é identificar a existência do princípio da invariância que demonstra que a forma como é apresentado o problema proporciona resultados diferentes, ou seja, mudança no comportamento dos tomadores de decisão. Apesar das questões serem apresentadas contendo o mesmo resultado, uma enquadra positivamente e a outra negativamente.

Para analisar se a forma como essas informações são escritas pode alterar o processo decisório, independentemente da preferência do indivíduo por esta ou aquela informação, foram criadas duas versões para cada trecho. Destaca-se, 
que o objetivo não foi identificar o melhor plano. Com este intuito, foram replicados os questionários (tipo 1 e 2), que seguem:

Quadro 2- Questão 1

1) Uma empresa de grande porte foi atingida recentemente por uma serie de dificuldades econômicas e parece que será obrigada a fechar três de suas fabricas, demitindo 6.000 empregados. O Vice Presidente de Produção tem investigado alternativas para evitar a crise e desenvolveu dois planos alternativos. Em relação a cada plano ele avalia o seguinte:

Tipo 01

Plano A: Este plano, se adotado, fecha duas das 3 fábricas e demite 4.000 empregados.

Plano B: Este plano se adotado, implica em $2 / 3$ de probabilidade de que as três fábricas serão fechadas, com perda dos 6.000 empregados, e $1 / 3$ de probabilidade de que as três fábricas serão salvas, e consequentemente com os 6.000 empregos mantidos.

\section{Tipo 02}

Plano A: Este plano, se adotado, salva uma das 3 fabricas e 2.000 empregados.

Plano B: Este plano, se adotado, implica em $1 / 3$ de probabilidade de que as três fábricas serão salvas, com 6.000 empregos mantidos, e $2 / 3$ de probabilidade de que não se salve nenhuma fábrica e consequentemente nenhum emprego.

O que você escolheria?

A. ( ) Plano A.
B. ( ) Plano B.

Fonte: Dantas e Macedo (2012, p.8)

São apresentadas abaixo duas tabelas: a Tabela 5 refere-se ao resultado da pesquisa aplicada aos profissionais de contabilidade, e a Tabela 6 refere-se aos resultados da pesquisa de Dantas e Macedo (2012) aplicados a estudantes de graduação em ciências contábeis.

Tabela 5 - Resultados da Questão 1

\begin{tabular}{l|c|c}
\hline \multirow{2}{*}{ Plano } & \multicolumn{2}{|c}{ Questão 1 } \\
\cline { 2 - 3 } & Tipo 1 & Tipo 2 \\
\hline Plano A & $33(33,33 \%)$ & $48(65,75 \%)$ \\
\hline Plano B & $66(66,67 \%)$ & $25(34,25 \%)$ \\
\hline Total & $99(100 \%)$ & $73(100 \%)$ \\
\hline
\end{tabular}

Fonte: Própria (2012)
Tabela 6 - Resultados da Questão 1

\begin{tabular}{l|c|c}
\hline \multirow{2}{*}{ Plano } & \multicolumn{2}{|c}{ Questão 1 } \\
\cline { 2 - 3 } & Tipo 1 & Tipo 2 \\
\hline Plano A & $53(49 \%)$ & $71(67 \%)$ \\
\hline Plano B & $56(51 \%)$ & $35(33 \%)$ \\
\hline Total & $109(100 \%)$ & $106(100 \%)$ \\
\hline
\end{tabular}

Fonte: Dantas e Macedo (2012)

$\mathrm{Na}$ Tabela 5 os profissionais da contabilidade que responderam o questionário tipo $01,33,33 \%$ escolheram o plano A, e $66,67 \%$ escolheram o plano $\mathrm{B}$; os profissionais que receberam o tipo dois, $65,75 \%$ escolheram o plano A e os $34,25 \%$ escolheram plano B.

Os questionários, que foram aplicados de maneira aleatória, confirmam que a apresentação dos dados alteram as respostas entre os grupos. Pode-se 
observar que no tipo 01 a preferência foi pelo plano B (maior proteção ao risco) enquanto no tipo 02 a escolha dos sujeitos foi pelo plano A indicando menor propensão ao risco.

Desta forma, o enquadramento da forma negativa os indivíduos são propensos ao risco (tipo 1), quanto se enquadra positivamente (tipo 2) a posição da perda passa a ser referência demonstrando um comportamento de aversão à perda. O resultado da questão evidencia que a forma como a informação gerencial foi escrita alterou significativamente a decisão dos respondentes, confirmando a teoria de Kahneman e Tversky (1979).

Sendo assim, corelacionando esta pesquisa com a pesquisa de Dantas e Macedo (2012), verifica-se que estatisticamente ocorre diferenças porem não altera o resultado. Desta forma, as duas pesquisas demonstram que no campo das perdas (questionário 1), os respondentes se mostram propensos ao risco, uma vez que a maioria optou pelo plano B. No campo dos ganhos (questionário 2), os respondentes mostraram-se avessos ao risco, escolhendo o plano A.

Nesta questão 3 o profissional é convidado a tomar uma decisão para cada uma das duas situações apresentadas. Sendo que na decisão 01 são apresentados em termo de ganho (positivo) e na decisão 02 são apresentados em forma de perda (negativa). Essa questão busca confirmar novamente o efeito Framing da Teoria dos Prospectos.

Quadro 3 - Questão 3

3) Você está diante de um par de decisão que terão que ser tomadas simultaneamente. Examine cada decisão e em seguida faça sua opção: (A) ou (B) na decisão 1 e (C) ou (D) na decisão 2. Decisão 01: Situação de corte de despesas administrativas:

A. ( ) Um lucro de $\$ 480,00$;

B. ( ) $25 \%$ de chances de lucrar \$2.000,00 e $75 \%$ chance de não lucrar nada.

Decisão 02: Situação de aumento de despesas tributárias:

C. ( ) Um prejuízo certo de $\$ 1.480,00$;

D. ( ) $75 \%$ de chance de perde $\$ 2.000,00$ e $25 \%$ chance de não perde nada.

Fonte: Dantas e Macedo (2012, p.8)

Tabela 7 - Resultados da Questão 3

\begin{tabular}{c|c}
\hline $\begin{array}{c}\text { Par de Decisões } \\
\text { Decisão 01 - Decisão 02 }\end{array}$ & Respondentes \\
\hline A - D & $53(30,81 \%)$ \\
\hline B - D & $65(37,79 \%)$ \\
\hline B - C & $20(11,63 \%)$ \\
\hline A- C & $34(19,77 \%)$ \\
\hline Total & $172(100 \%)$ \\
\hline
\end{tabular}

Fonte: Própria (2012)
Tabela 8 - Resultados da Questão 3

\begin{tabular}{c|c}
\hline $\begin{array}{c}\text { Par de Decisões } \\
\text { Decisão 01 - Decisão 02 }\end{array}$ & Respondentes \\
\hline A - D & $87(41 \%)$ \\
\hline B - D & $65(31 \%)$ \\
\hline B - C & $19(9 \%)$ \\
\hline A-C & $41(19 \%)$ \\
\hline Total & $212(100 \%)$ \\
\hline
\end{tabular}

Fonte: Dantas e Macedo (2012, p.9) 
$\mathrm{Na}$ pesquisa realizada com estudantes, comprovou-se na Teoria dos Prospectos uma abordagem com viés do enquadramento dos resultados, e na pesquisa com os profissionais de contabilidade verificou-se o viés heurístico no que tange à autoconfiança excessiva (Overconfidence), representado por 37,79\%, o que leva a crer, diante da comparação entre profissionais e estudantes, que aqueles assumem esta característica por se apresentarem com maior tempo de experiência profissional na área. Os profissionais se consideram conhecedores do mercado, sobreestimando as suas próprias habilidades. Entretanto, essa temática não é o foco deste artigo.

Analisando em pares de decisões, agora correlacionando B e C, verificouse que na percepção dos estudantes e dos profissionais da contabilidade, $9 \%$ e $11,63 \%$ respectivamente, houve uma concentração de menor proporcionalidade nos dois estudos, indicando que estes se utilizam mais da teoria comportamental em detrimento da teoria moderna, Teoria da Utilidade Esperada (TUE). A TUE indica que a melhor escolha, seria aquela que melhor agregasse valor, ou seja, a que possui um maior risco.

Quadro 04 - Questões 2 e 4

2) Você está na função de "controller" e está realizando um processo de escolha de projetos de investimentos em TI - Tecnologia da Informação. O processo de escolha deve ocorrer em duas etapas. A $1^{\text {a }}$ etapa é uma análise da solidez financeira do projeto, e existe $75 \%$ de chance do processo terminar neste momento sem lucro nenhum e $25 \%$ de chance de o projeto que você está analisando passar para a $2^{\underline{a}}$ etapa. Na segunda etapa, você tem que escolher entre duas opções de projeto. Você precisa definir sua escolha antes do início do processo. Qual das duas opções abaixo você escolheria?

A. ( ) Este projeto se escolhido gera com certeza um lucro de $\mathrm{R} \$ 100$ mil.

B. ( ) Este projeto se escolhido tem $80 \%$ de chance de gerar um lucro de $\mathrm{R} \$ 150 \mathrm{mil}$.

4) Você é o planejador financeiro e deverá escolher entre duas alternativas que podem diminuir as despesas com material de escritório da empresa. Qual você escolheria?

A. ( ) Este alternativa se escolhida tem $25 \%$ de chance de economizar $\mathrm{R} \$ 100$ mil.

B. ( ) Esta alternativa se escolhida tem 20\% de chance de economizar R\$150 mil.

Decisão 02: Situação de aumento de despesas tributárias:

A. ( ) Um prejuízo certo de $\$ 1.480,00$;

B. ( ) $75 \%$ de chance de perde $\$ 2.000,00$ e $25 \%$ chance de não perde nada.

Fonte: Dantas e Macedo (2012, p.10)

Conforme demonstrado abaixo, as questões 2 e 4 são analisados em pares e posteriormente individualmente. $\mathrm{O}$ objetivo é testar a existência de pseudocerteza como na teoria dos prospectos, a qual defende que os indivíduos 
atribuem menos peso a evento de alta probabilidade, entretanto ponderando eventos considerados certos.

Em termos de valor esperado a teoria de utilidade esperada (racional) indica que a melhor opção seria a associação da B da Questão 2 com a B da Questão 4.

Para se confirmar o viés da pseudocerteza, a questão teria a combinação da escolha A para a questão 2 e da escolha B para a questão 4.

$\mathrm{Na}$ pesquisa realizada sob a perspectiva dos estudantes observou-se um certo equilíbrio entre a TUE (39\%) e o viés da pseudocerteza (40\%). E na perspectiva do profissional da contabilidade, tendo por base a mesma correlação, concentram-se em maior proporção na escolha que reflete o maior valor esperado $(37,8 \%)$.

Tabela 9 - Resultados das Questões 2 e 4 (em conjunto)

\begin{tabular}{c|c}
\hline $\begin{array}{c}\text { Par de Decisões } \\
\text { Questão 02 - Questão 04 }\end{array}$ & Respondentes \\
\hline A - B & $30(17,44 \%)$ \\
\hline B - B & $65(37,80 \%)$ \\
\hline B - A & $35(20,35 \%)$ \\
\hline A - A & $42(24,41 \%)$ \\
\hline Total & $172(100 \%)$ \\
\hline
\end{tabular}

Fonte: Própria (2012)
Tabela 10 - Resultados das Questões 2 e 4 (em conjunto)

\begin{tabular}{c|c}
\hline $\begin{array}{c}\text { Par de Decisões } \\
\text { Questão 02 - Questão 04 }\end{array}$ & Respondentes \\
\hline A - B & $85(40 \%)$ \\
\hline B - B & $84(39 \%)$ \\
\hline B - A & $24(11 \%)$ \\
\hline A - A & $22(10 \%)$ \\
\hline Total & $215(100 \%)$ \\
\hline
\end{tabular}

Fonte: Dantas e Macedo (2012, p.9)

Analisando a questão 4 individualmente, numericamente é diferente; entretanto, estatisticamente se aproxima com uma concentração na escolha da opção B (maior valor esperado). Ao passo que a questão dois na pesquisa realizada com estudantes confirma um equilíbrio de $50 \%$ para cada uma das opções, e na pesquisa feita com os profissionais identificou-se estatisticamente $8 \%$ a mais de concentração na opção B (58\%).

\subsection{Análise da Significância teste $\mathbf{R}^{2}$}

A análise do nível de significância do teste qui-quadrado, como demonstrado na Tabela 13, indica que existe diferença estatística entre as respostas da questão 1 nos dois questionários, o $R^{2}$ foi de 0,000 , ou seja, essa variável confirma que o padrão de resposta do questionário 1 é estatisticamente diferente do questionário 2, tanto para Natal/RN quanto para Belém/RN. 


\begin{tabular}{l} 
Tabela 11 - Resultado Teste $\mathrm{R}^{2}$ questão 1 \\
\hline \multicolumn{3}{c|}{ Chi-Square Tests } \\
\hline
\end{tabular}

Para questão 02, apresentaram-se duas opções de projetos, opção A correspondente a um projeto que se escolhido, o individuo teria um lucro certo de 100 mil e o projeto $B$, que se escolhido teria $80 \%$ de gerar 150 mil de lucro. Foi solicitado aos respondentes que optassem por um destes projetos.

Comparando as escolhas dos respondentes de Natal/RN e Belém/PR, pode-se perceber que, conforme a Tabela 11, os respondentes dos dois estados optaram pelo projeto B, sendo Natal/RN apresentando um percentual de 59,3\% e Belém por $56,30 \%$.

Utilizando-se da estatística qui-quadrado de Pearson (Teste $\chi^{2}$ ), para comparar o nível de respostas entre os dois Estados, encontra-se que $R^{2}=1,75$ e $o$ nível de significância foi de 0,415 , isto significa que não houve diferença no padrão de respostas entre as duas cidades, ou seja, houve o mesmo posicionamento.

Tabela 12 - Resultado Teste $\mathrm{R}^{2}$ questão 2

\begin{tabular}{l|c|c}
\hline & Natal/RN & Belém/PA \\
\hline Respondentes & 32 & 63 \\
\hline$\%$ & $59,30 \%$ & $56,30 \%$ \\
\hline Escolha & B & B \\
\hline Teste $X^{2}$ & \multicolumn{2}{|c}{1,75} \\
\hline Nível de confiança & \multicolumn{2}{|c}{0,415} \\
\hline
\end{tabular}

Fonte: Própria, 2012.

A questão 03 é composta por um par de decisões que devem ser tomadas simultaneamente, onde na Decisão 01 o individuo estará diante de corte de despesas administrativas, que optará pela opção A tendo um lucro certo de $\mathrm{R} \$$ 480,00 ou opção B que se o individuo optar por esta terá $25 \%$ de chance de lucrar R\$2.000,00 ou 75\% de não lucrar nada. Na Decisão 02 o individuo estará diante de uma situação de aumento de despesas tributárias, que poderá optar pela opção $C$, que expressa um prejuízo certo de $\mathrm{R} \$ 1.480,00$ ou opção $\mathrm{D}$ que terá $75 \%$ de perder $\mathrm{R} \$ 2.000,00$ ou $25 \%$ de nada perder. De acordo com a Tabela 
13, referente a Decisão 01, os respondentes da cidade de Natal/RN optaram pela opção A, representando $57,4 \%$ e os respondentes da cidade de Belém/PA optaram pela opção B $(53,6 \%)$. Não há como dizer que o nível de resposta entre as duas cidades é diferente, já que o Pearson (Teste $\chi^{2}$ ), foi de $\mathrm{R}^{2}=2,4$ e o nível de significância 0,301. Já na Decisão 02 tanto Natal/RN quando Belém/PAA optaram a maioria pela opção $\mathrm{D}$, representando respectivamente, $74,1 \%$ e $64,3 \%$, conforme Tabela 16. Utilizando-se o teste estatístico qui-quadrado de Pearson (Teste $\chi^{2}$ ), $R^{2}=4,46$ e o nível de significância foi de 0,107 é possível concluir que o padrão de resposta entre as duas cidades é estatisticamente igual.

Tabela 13 - Resultado Teste R² questão 3

DECISÃO 01

\begin{tabular}{l|c|c}
\hline & Natal/RN & Belém/PA \\
\hline Respondentes & 31 & 60 \\
\hline$\%$ & $57,40 \%$ & $53,60 \%$ \\
\hline Escolha & A & B \\
\hline Teste $R^{2}$ & \multicolumn{2}{|c}{2,4} \\
\hline $\begin{array}{l}\text { Nível de } \\
\text { confiança }\end{array}$ & \multicolumn{2}{|c}{0,301} \\
\hline
\end{tabular}

Fonte: Própria, 2012.
Tabela 14 - Resultado Teste $\mathrm{R}^{2}$ questão 3

DECISÃO 02

\begin{tabular}{l|c|c}
\hline & Natal/RN & Belém/PA \\
\hline Respondentes & 40 & 72 \\
\hline$\%$ & $74,10 \%$ & $64,30 \%$ \\
\hline Escolha & $\mathrm{D}$ & $\mathrm{D}$ \\
\hline Teste $\mathrm{R}^{2}$ & \multicolumn{2}{|c}{4,46} \\
\hline $\begin{array}{l}\text { Nível de } \\
\text { confiança }\end{array}$ & \multicolumn{2}{|c}{0,107} \\
\hline
\end{tabular}

Fonte: Própria, 2012.

Para concluir os resultados, foi analisada também a questão 04, através do estatístico qui-quadrado de Pearson (Teste $\chi^{2}$ ). Nesta questão insere o individuo no contexto como sendo planejador financeiro que deverá escolher entre duas alternativas, que poderão reduzir as despesas com material de escritório. A alternativa A se escolhida o individuo terá $25 \%$ de economizar 100 mil e a alternativa B diz que se escolhida o individuo terá $20 \%$ de chances de economizar 150 mil. De acordo com a Tabela 15, verificou-se que ambas as cidades optaram pela alternativa $B$, representando respectivamente $61,1 \%$ e $52,7 \%$, e utilizando-se o teste estatístico, observou-se que $R^{2}=1,11$ e o nível de significância foi de 0,572, também inferindo que o padrão de resposta é estatisticamente igual.

Tabela 15 - Resultado Teste $R^{2}$ questão 4

\begin{tabular}{l|c|c}
\hline & Natal/RN & Belém/PA \\
\hline Respondentes & 33 & 59 \\
\hline$\%$ & $61,10 \%$ & $52,70 \%$ \\
\hline Escolha & B & B \\
\hline Teste R & \multicolumn{2}{|c}{1,11} \\
\hline Nível de confiança & \multicolumn{2}{|c}{0,572} \\
\hline
\end{tabular}

Fonte: Própria, 2012. 


\section{CONSIDERAÇÕES FINAIS}

O objetivo deste artigo foi analisar o impacto da racionalidade limitada em um ambiente de decisão com base em informações contábeis na perspectiva de profissionais de contabilidade e, de maneira secundária, relacionando o efeito Framing com perfil demográfico. Intrinsecamente, buscou-se correlacionar semelhanças e divergências com a pesquisa de Dantas e Macedo (2012) que utilizaram como amostra os estudantes de contabilidade.

Baseando-se na teoria dos Prospectos de Kahneman e Tversky (1979) verificou-se nesta pesquisa a existência do efeito framing na questão 1, quando houve manipulação na apresentação do problema enquadrado positivamente e negativamente. Assim o resultado da questão evidenciou que os profissionais, quando expostos a situações negativas são propensos ao risco e, quando expostos a situações positivas, possuem aversão à perda. Esses achados coincidiram com os da pesquisa aplicada com os estudantes.

$\mathrm{Na}$ questão 3, a teoria dos prospectos é identificada quando o respondente associa a alternativa $\mathrm{A}$ da primeira decisão com a $\mathrm{D}$ da segunda decisão. Na pesquisa apenas 30,81\% realizaram esta associação, e em outra parte, sendo o maior percentual, 37,79\%, verificou-se a utilização de viés heurístico no que tange à autoconfiança excessiva (Overconfidence). Este ponto diferencia-se da pesquisa com estudantes, pois a maior concentração (41\%) se deu com ênfase na teoria dos prospectos, utilizando-se da abordagem com viés do enquadramento dos resultados.

Nos resultados observados nas questões 2 e 4, que verificam o efeito da pseudocerteza, observou-se que 17,44\% dos profissionais de contabilidade foram influenciados por uma manipulação da certeza. Entretanto, na pesquisa realizada com estudantes, essa influencia foi de 40\%; assim, pode-se inferir que os profissionais são menos influenciados pela manipulação da certeza.

Utilizou-se também o teste estatístico qui-quadrado de Pearson (Teste $\chi^{2}$ ), para averigua o padrão de respostas dos respondentes da cidade de $\mathrm{Natal} / \mathrm{RN}$ e a cidade de Belém/PA. Nas questões 02 a 04, pode-se observar que não houve diferença no padrão de respostas. Já na questão 01 foi a única que se identificou padrão de respostas significamente diferentes entre as duas cidades.

Os achados deste artigo corroboram os resultados de estudos anteriores, dentre os quais destacam-se: Pinto, Macedo e Alves (2012), Macedo e Fontes (2009), Mendonça Neto et al (2009) e Cardoso, Riccio e Lopes (2008).

Assim como outros estudos confirmam a teoria dos prospectos, este trabalho vem contribuir com a observação da ocorrência do framing em profissionais de contabilidade; porém, observou-se também que estes utilizam a racionalidade limitada visando à tomada de decisão focada no mercado e 
utilizando-se do viés heurístico (autoconfiança excessiva) sem secundarizar o apreço pelo maior valor agregado.

\section{REFERÊNCIAS}

ANDRADE, R. O. B.; ALYRIO, R. D.; MACEDO, M. A. S. Princípios de negociação: ferramentas e gestão. 2. ed. São Paulo: Atlas, 2007.

ARIELY, Dan. Previsivelmente irracional: as forças ocultas que formam as nossas decisões. Tradução de Jussara Simões. Rio de Janeiro: Alsevier, 2008.

BRIGHAM, Eugene F.; EHRHARDT, Michael C. Administração financeira: teoria e prática. São Paulo: Pioneira Thomson Learning, 2006.

CARVALHO JUNIOR, César Valentim de Oliveira; ROCHA, Joséilton Silveira; BRUNI, Adriano Leal. O Aprendizado Formal de Controladoria e a minimização do Efeito Framing: um estudo de decisões gerenciais envolvendo Custos de Oportunidade. REPeC - Revista de Educação e Pesquisa em Contabilidade, v. 3, n. 3, art. 2, p. 18-39, 2009.

CHANCELLOR, Edward. Salve-se quem puder: uma história da especulação financeira. São Paulo: Companhia das Letras, 2001.

DAFT, Richard. Administração. LTC - Livros Técnicos e Científicos. Editora S.A. Rio de Janeiro. 1999.

DANTAS, Manuela Moura; MACEDO, Marcelo Álvaro Da Silva. O Processo Decisório no Ambiente Contábil: Um Estudo à Luz da Teoria dos Prospectos. In: CONGRESSO USP DE INICIAÇÃO CIENTIFICA EM CONTABILIDADE, São Paulo/SP, 9, 2012. Anais... São Paulo/SP, FEA/USP, 2012.

DANTAS, Manuela Moura; MACEDO, Marcelo Álvaro da Silva. O processo decisório no ambiente contábil: um estudo à luz da teoria dos prospectos. In: CONGRESSO DE INICIAÇÃO CIENTÍFICA EM CONTABILIDADE, São Paulo/SP, 9., 2012. Anais... São Paulo/SP: FEA/USP, 2012.

FAMÁ, Rubens; CIOFFI, Patrícia Leite de Moraes; COELHO, Paula Augusta Rodrigues. Contexto das finanças comportamentais: anomalias e eficiência do Mercado de Capitais Brasileiro. Revista de Gestão USP, v. 15, n. 2, p. 65-78, abr./jun. 2008.

FIELD, Andy. Discovering Statistics using SPSS for Windows. London: Sage, 2000. 
GONZÁlEZ RÍO, María José. Metodología de la Investigación Social. Técnicas de recolección de datos. Spain: Aguaclara, 1997.

HALFELD, Mauro; TORRES, Fábio de Freitas Leitão. Finanças comportamentais: aplicações no contexto brasileiro. Revista de Administração de Empresas (RAE), v. 41, n. 2, p. 64-71, abr./jun. 2001.

IUDÍCIBUS, Sérgio de. Análise de balanços. 10. ed. São Paulo: Atlas, 2009.

KAHNEMAN, D. P.; TVERSKY, A. Prospect theory: an analysis of decision under risk. Econometrica, v. 47, p. 263-291, 1979.

LEVIN, I. P.; GAETH, G. J.; SCHREIBER, J. A new look at framing effects: distribution of effect sizes, individual differences, and independence of types of effects. Organizational Behavior and Human Decision Processes, v. 88, n. 1, p. 411-429, 2002.

LIMA, Murillo Valverde. Um estudo sobre finanças comportamentais. RAE Eletrônica, v.2, n. 1, jun. 2003.

LONGARAY, André Andrade; BEUREN, Ilse Maria. Decisões organizacionais: as perspectivas qualitativas, quantitativas e a abordagem multicritérios. Anais do Encontro Nacional de Engenharia de Produção. Florianópolis: 2001. Disponível em: <http://www.abepro.org.br/biblioteca/ENEGEP2001_TR62_0087.pdf>. Acesso em: 07 jun.2012

MACEDO, Macelo Álvaro da Silva, FONTES, Patrícia Vivas da Silva. Análise do comportamento decisório de analistas contábil-financeiros: um estudo com base na teoria da racionalidade limitada. Revista Contemporânea de Contabilidade, v. 1, n. 11, p. 159-186, jan./jun. 2009. Disponível em: $<$ http://journal.ufsc.br/index.php/contabilidade/article/view/11185>. Acesso em: 07 jun. 2012.

MACEDO JR., Jurandir Sell. Teoria do Prospecto: uma investigação utilizando simulação de investimentos. Florianópolis: UFSC, 2003. 203 p. Tese (Doutorado em Engenharia de Produção). Programa de Pós-Graduação em Engenharia de Produção, Universidade Federal de Santa Catarina, Florianópolis, 2003.

MARION, José Carlos. Contabilidade Empresarial. São Paulo: Atlas, 2009. 
MILANEZ, Daniel Yabe. Finanças comportamentais no Brasil. Dissertação (Mestrado em Economia das Instituições e do Desenvolvimento) - Faculdade de Economia, Administração e Contabilidade, Universidade de São Paulo, São Paulo, 2003.

MOSCA, Aquiles. Finanças comportamentais: gerencie suas emoções e alcance sucesso nos investimentos. Rio de Janeiro: Elsevier, 2009.

PINTO, Patrycia Scavello Barreto; MACEDO, Marcelo Álvaro Da Silva; ALVES, Francisco Jose Dos Santos. Tomada de decisão e teoria dos prospectos em ambiente contábil: uma análise com foco no efeito framing. In: $12^{\circ}$ Congresso De Controladoria e Contabilidade, 2012. São Paulo/Sp. Fea/Usp, 2012.

ROGERS, Pablo; SECURATO; José Roberto, RIBEIRO, Kárem C. S.; ARAÚJO, Simone R. Finanças comportamentais no Brasil: um estudo comparativo. In: CONGRESSO DE INICIAÇÃO CIENTÍFICA EM CONTABILIDADE DA USP, 7., 2007, São Paulo. Anais... São Paulo: USP, 2007.

SANTOS, Ticiane Lima dos. Os estilos de liderança nas organizações não governamentais. Dissertação (Mestrado em Administração ). Programa Pós Graduação em Administração da Universidade Federal do Rio Grande do Norte, 2010.

SHEFRIN, Hersh. Beyond greed and fear: understanding Behavioral Finance and the Psychology of Investing. Boston: Oxford University Press, 2002.

SIEGEL, Sidney; CASTELLAN Jr., N. John. Estátistica Não-Paramétrica para Ciências do Comportamento. Trad. Sara Ianda Correa Carmona. Porto Alegre: Artmed, 2006.

SIMON, H. A. A behavioral model of rational choice. Quarterly Journal of Economics, v. 69, p. 99-118, 1955.

VERGARA, Sylvia Constant. Projetos e relatórios de pesquisa em administração. 5. ed. São Paulo: Atlas, 2004.

VYGOTSKY, L.S. Pensamento e linguagem. São Paulo: Martins Fontes, 1987.

YOSHINAGA, Claudia Emiko; OLIVEIRA, Raquel Freitas de; SILVEIRA, Alexandre Di Miceli da; BARROS, Lucas Ayres B. de C. Finanças Comportamentais: uma introdução. In: SEMINÁRIOS DE ADMINISTRAÇÃO DA FEA-USP, 7., 2004, São Paulo. Anais... São Paulo: USP, 2004. 